\title{
OPEN Anchoring Pd-nanoparticles on dithiocarbamate- functionalized SBA-15 for hydrogen generation from formic acid
}

\author{
Mustafa Farajzadeh ${ }^{1}$, Hassan Alamgholiloo ${ }^{1}$, Fariba Nasibipour ${ }^{1}$, Reza Banaei ${ }^{1}$ \& \\ Sadegh Rostamnia ${ }^{1,2 \bowtie}$
}

Hydrogen $\left(\mathrm{H}_{2}\right)$ generation from natural biological metabolic products has remained a huge challenge for the energy arena. However, designing a catalytic system with complementary properties including high surface area, high loading, and easy separation offers a promising route for efficient utilization of nanoreactors for prospective $\mathrm{H}_{2}$ suppliers to a fuel cell. Herein, selective dehydrogenation of formic acid (FA) as a natural biological metabolic product to $\mathrm{H}_{2}$ and $\mathrm{CO}_{2}$ gas mixtures has been studied by supporting ultrafine palladium nanoparticles on organosulfur-functionalized SBA-15 nanoreactor under ultrasonic irradiation. The effects of the porous structure as a nanoreactor, and organosulfur groups, which presented around the Pd due to their prominent roles in anchoring and stabilizing of $\mathrm{Pd}$ NPs, studied as a superior catalyst for selective dehydrogenation of FA. Whole catalytic systems were utilized in ultrasonic irradiation in the absence of additives to provide excellent TOF/TON values. It was found that propose catalyst is a greener, recyclable, and more suitable option for the large-scale application and provide some new insights into stabilization of ultra-fine metal nanoparticle for a variety of applications.

It is clear that fossil fuel reserves are limited and some environmental problems such as ozone depletion, acid rain, and some other issues in this case that is arising from the presence of $\mathrm{CO}_{2}, \mathrm{NO}_{\mathrm{x}}$, and $\mathrm{SOx}$ in the publication gases, ensue because of consuming coal, natural gas and petroleum ${ }^{1,2}$. Most of these problems can be crossed by using clean and renewable energy sources. Hydrogen $\left(\mathrm{H}_{2}\right)$ is the globally accepted and most suitable and clean energy source, which could solve the world energy problem and diminish the environmental pollution emanated from fossil fuels ${ }^{3}$. Formic acid $(\mathrm{HCOOH}, \mathrm{FA})$ is an appropriate liquid for storage and hydrogen production because it normally is non-toxic, available from some process like the reduction of carbon dioxide or biomass processing, and has a significant content of hydrogen $(4.4 \mathrm{wt} \%)$ at room temperature ${ }^{4-6}$. Besides, FA can readily release $\mathrm{H}_{2}$ under room temperature in the presence of homogeneous and heterogeneous catalysts under the reaction: $\mathrm{HCOOH} \rightarrow \mathrm{CO}_{2}+\mathrm{H}_{2}$.

Recently, tremendous efforts have been made for selective dehydrogenation of FA with homogeneous ${ }^{7-14}$ and heterogeneous catalysts ${ }^{15-24}$, which have their own unbeatable advantages. Despite the homogeneous catalysts based on Ir, Ru, and Fe organometallic complex usually have great catalytic activity and selectivity, while gold ${ }^{25}$, Platinum $^{26}$, and palladium ${ }^{4}$ well known heterogeneous catalysts used in the decomposition of FA. However, some reports have shown that nanostructure with base $\mathrm{Pd}$ such as $\mathrm{Au}_{0.5} \mathrm{Pd}_{0.5} / \mathrm{NH}_{2}-\mathrm{N}-\mathrm{rGO}{ }^{27}, \mathrm{Pd}-\mathrm{MIL}-125^{28}$, $\mathrm{Pd}_{1} \mathrm{Au}_{1} / 30-\mathrm{LA}^{29}, \mathrm{AP} \mathrm{SiO}_{2} @ P D A-N G O @ P{ }^{30}, \mathrm{PdAu}-\mathrm{MnOx} / \mathrm{N}-\mathrm{SiO}_{2}{ }^{31}, \mathrm{CrAuPd} / \mathrm{N}-\mathrm{SiO}_{2}{ }^{32}, \mathrm{IrPdAu} / \mathrm{NH}_{2}-\mathrm{SBA}-15^{33}$, $\mathrm{Ag}_{0.2} \mathrm{Au}_{0.4} \mathrm{Pd}_{0.4} / \mathrm{rGO}^{34}, \mathrm{Au} @ \mathrm{Pd} / \mathrm{UiO}-66\left(\mathrm{Zr}_{\mathrm{x}} \mathrm{Ti}_{\mathrm{y}}\right)^{35}, \mathrm{Au}-\mathrm{Pd} / \mathrm{MIL}-101^{36}$, and PdCoNi/TiO ${ }^{37}$, can efficiently decomposed FA under neat condition. Recently, our research group explored the catalytic application of Pd@Cu-MOF ${ }^{38}$ and Pd@Cr-MOF ${ }^{39}$ with open metal sites as an ideal Pd-catalyst for $\mathrm{H}_{2}$ generation from FA in neat condition. Despite the inspiring progress, selective dehydrogenation of FA still suffers from some significant limitations such as low conversion, highly Metal-dependent, and large energy consumption.

Ultrasonic technology is a safe and efficient new treatment method for the chemical transformations and environmental arena. This technology has advantages such as high efficiency, short reaction time due to local temperature, high pressure and cooling speed ${ }^{40-44}$. However, despite the unique ultrasonic technology and their

${ }^{1}$ Organic and Nano Group (ONG), Department of Chemistry, Faculty of Science, University of Maragheh, PO BOX, 55181-83111 Maragheh, Iran. ${ }^{2}$ Organic and Nano Group (ONG), Department of Chemistry, Iran University of Science and Technology (IUST), PO Box, 16846-13114 Tehran, Iran. $₫$ email: rostamnia@maragheh.ac.ir 
effect in catalytic systems for energy arena such as selective dehydrogenation has been unexplored to date. However, despite the unique ultrasonic technology and their effect in catalytic systems for energy arena such as selective dehydrogenation has been unexplored to date. On the other hand, dithiocarbamate (DTC) ligands possess well coordination capability, versatile coordination modes, and unique chemical properties of their metal complexes and nanoparticles ${ }^{45-48}$. The best affinity between the DTC ligand and the template walls is basically important for grafting and stabilizing the Pd NPs, and inhibition of the "Ostwald Ripening" process. Based on the above considerations, we envisioned an economical method for the bifunctional fabrication catalyst with features such as benign environmental, stable, and affordable for selective dehydrogenation of aqueous solutions of $\mathrm{HCOOH}$ We exploited both metal and organosites for the sustainability for $\mathrm{H}_{2}$ generation from FA. The resultant of $\mathrm{Pd}_{\mathrm{NPs}} @ \mathrm{SBA}-15 / \mathrm{DTC}$ with uniform pores exhibit excellent catalytic activity in the presence of ultrasonic wave as a synergistic agent with the turnover frequency (TOF) value of $1952 \mathrm{~h}^{-1}$, turnover number (TON) value of 3904 and $9.86 \mathrm{~mL}$ of gas $\left(\mathrm{H}_{2}\right.$ and $\left.\mathrm{CO}_{2}\right)$ was obtained in $120 \mathrm{~min}$.

\section{Experimental}

Materials and methods. Tetraethyl orthosilicate (TEOS, Aldrich, 99.8\%), poly(ethylene glycol)-blockpoly(propylene glycol)-block-poly(ethylene glycol) (P123, Aldrich), 3-aminopropyl triethoxysilane (Merck, 99.9\%), $\mathrm{PdCl}_{2}$ (Merck, 99.5\%), $\mathrm{CS}_{2}$ anhydrous (Aldrich, $\geq 99 \%$ ), Formic acid (Aldrich, $\geq 95 \%$ ), ethanol (Merck, 98.5\%), $\mathrm{CH}_{3} \mathrm{CN}$ (Merck, 99.5\%), and methanol (Merck, 99.5\%) were used without further purification. Ultrapure water with the specific resistivity of $18.5 \mathrm{M} \Omega \mathrm{cm}$ was used for all experiments.

Characterization. The FT-IR spectra were performed using a PerkinElmer-Spectrum Two with ATR probe. The morphologies of the samples were taken on FE-SEM, Zeiss EM 960 A. The TEM images were recorded on Zeiss-EM10C-100 kV. The volume of gases $\left(\mathrm{H}_{2}+\mathrm{CO}_{2}\right)$ analyzed by a gas chromatograph (GC) and negligible carbon monoxide $(\mathrm{CO})$ evolution was observed. The results compared with obtained information from the automatic sensor of $\mathrm{H}_{2}$ and $\mathrm{CO}_{2}$ gases.

Preparation of SBA-15/DTC. SBA-15 nanoreactor was synthesized a supramolecular self-assembly strategy according to our previous method ${ }^{49,50}$ and other reports ${ }^{51-53} .1 .0 \mathrm{~g}$ of calcined SBA- 15 was dried at $120^{\circ} \mathrm{C}$ under vacuum for $6 \mathrm{~h}$. After this, the solid material was dispersed in $25 \mathrm{~mL}$ of dried-toluene under inert atmosphere and after adding $2 \mathrm{mmol}$ of 3-aminopropyl triethoxysilane (APTES) to the mixture refluxed for $2 \mathrm{~h}$ at $110{ }^{\circ} \mathrm{C}$. Finally, the solid white product was separated and washed multiple times by DI-water and methanol. Then, $\mathrm{CS}_{2}(1 \mathrm{mmol})$ was added to the mixture with a few drops $\mathrm{NH}_{3}$ and stirred at ambient condition for $12 \mathrm{~h}$. Finally obtained (SBA-15/DTC) was collected and washed with $\mathrm{EtOH}$ and then dried for $5 \mathrm{~h}$ at $70{ }^{\circ} \mathrm{C}$.

Preparation of $\mathrm{Pd}_{\mathrm{NPs}}$ @SBA-15/DTC. $\mathrm{PdCl}_{2}(100 \mathrm{mg})$ was dissolved in $\mathrm{DI}-\mathrm{H}_{2} \mathrm{O}$ and $\mathrm{CH}_{3} \mathrm{CN}(1: 1 \mathrm{v} / \mathrm{v}$, $5 \mathrm{~mL})$ and this solution was added to a suspension of SBA-15/DTC (500 mg) in EtOH (25 mL). After stirring for $2 \mathrm{~h}$ at ambient condition, the resulting solid material was collected, washed 2 times with EtOH, 1 time with $\mathrm{CH}_{2} \mathrm{Cl}_{2}$ and dried at room temperature for $12 \mathrm{~h}$. Then the solid result was dispersed in $10 \mathrm{~mL} \mathrm{MeOH}$ and a solution $10 \mathrm{mM}_{\text {of }} \mathrm{NaBH}_{4}$ was added dropwise. After stirring for $2 \mathrm{~h}$ at ambient condition, the final solid result was collected by filtration, washed with $\mathrm{MeOH}$ and $\mathrm{CH}_{2} \mathrm{Cl}_{2}$ for several times and dried at room temperature. According to atomic absorption analysis (AAS) of the Pd-catalyst, the amount of loaded Pd was $0.010 \mathrm{mmol}$ per gr of catalyst.

Catalytic dehydrogenation of FA. Catalytic dehydrogenation of FA was accomplished in a two-necked round bottom flask (volume, $80 \mathrm{~mL}$ ). One neck of the flask is connected to a gas burette and the other was reserved for adding $50 \mathrm{mg}$ of Pd-catalyst mixed with $5.0 \mathrm{ml}$ of FA-SF (FA: $5 \% \mathrm{v} / \mathrm{v}$ with a mole ratio of 1:1) under ultrasonic irradiation. To examine whether or not $\mathrm{CO}$ gas was formed in the dehydrogenation process, the generation gases analyzed by GC and $\mathrm{NaOH}$ trap experiment. Using $6.64 \mathrm{mmol}$ of FA under ultrasonic irradiation, the complete conversion is expected to develop $9.86 \mathrm{~mL}$ of the gases mixture with TOF value of $1952 \mathrm{~h}^{-1}$, as calculated from the following equation.

$$
T O F_{\text {initial }}=\frac{P_{a t m} V_{g a s} / R T}{2 n_{p d} t}
$$

TOF was obtained from decomposition of FA/SF (1:1), which Patm is atmospheric pressure, Vgas is volume of produced gas, $R$ is universal gas constant, $T$ is room temperature and $n_{\mathrm{Pd}}$ is mole number of $\mathrm{Pd}$ in the catalyst.

\section{Results and discussion}

In this study, SBA-15 was prepared a supramolecular self-assembly strategy and then dithiocarbamate grafted on $3 \mathrm{D}$ ordered mesoporous silica. The resulted white powder was then utilized as the excellent support for immobilizing ultra-fine Pd NPs Fig. 1. The hydrophobic-hydrophilic properties of the mesoporous silica are controlled By embedding the DTC ligand into the pore walls. Plus, the DTC ligand and pores structure of nanoreactor SBA- 15 has a vital role in the excellent control of Pd metal size and homogeneous dispersion, of that, then boosting the catalytic activity for selective dehydrogenation of FA.

The chemical groups of the SBA-15, DTC/SBA-15, and Pd $\mathrm{NPs}_{\mathrm{N}} @ \mathrm{SBA}-15 / \mathrm{DTC}$ were analyzed by FTIR spectra. As depicted in Fig. 2a, several absorption bands in 1400-1700 can be ascribed to ligand DTC in the SBA-15/DTC framework. The signal appears in $3241 \mathrm{~cm}^{-1}$ is attributed to $\mathrm{N}-\mathrm{H}$ stretch mode, which suggesting the successful 


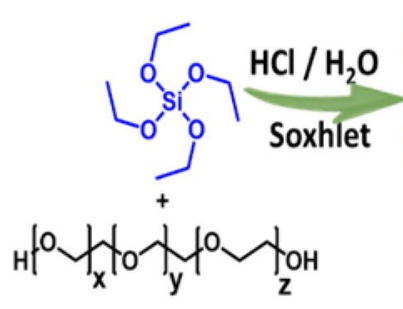

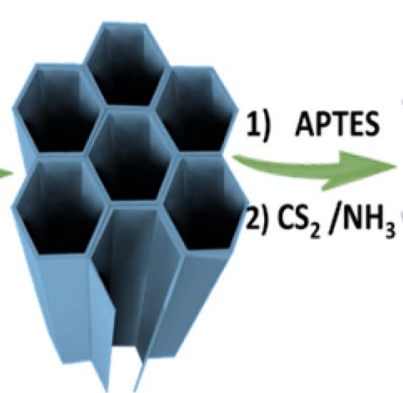

Calcined SBA-15

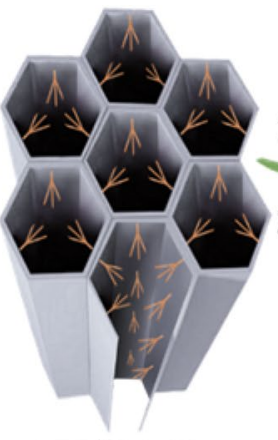

DTC/SBA-15
1) $\mathrm{PdCl}_{2}$

2) $\mathrm{NaBH}_{4}$

$0.1 \mathrm{M}$

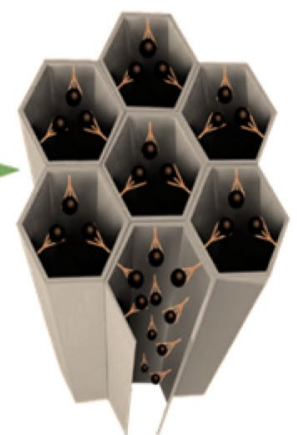

$P d_{N P S} @ S B A-15 / D T C$
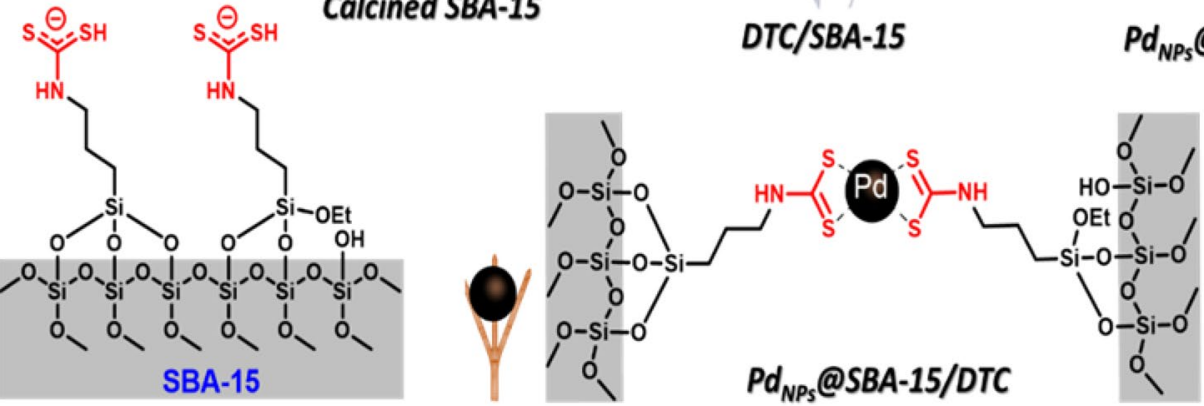

Figure 1. Schematic illustration for preparation of the $\mathrm{Pd}_{\mathrm{NPs}} @ S B A-15 / \mathrm{DTC}$.
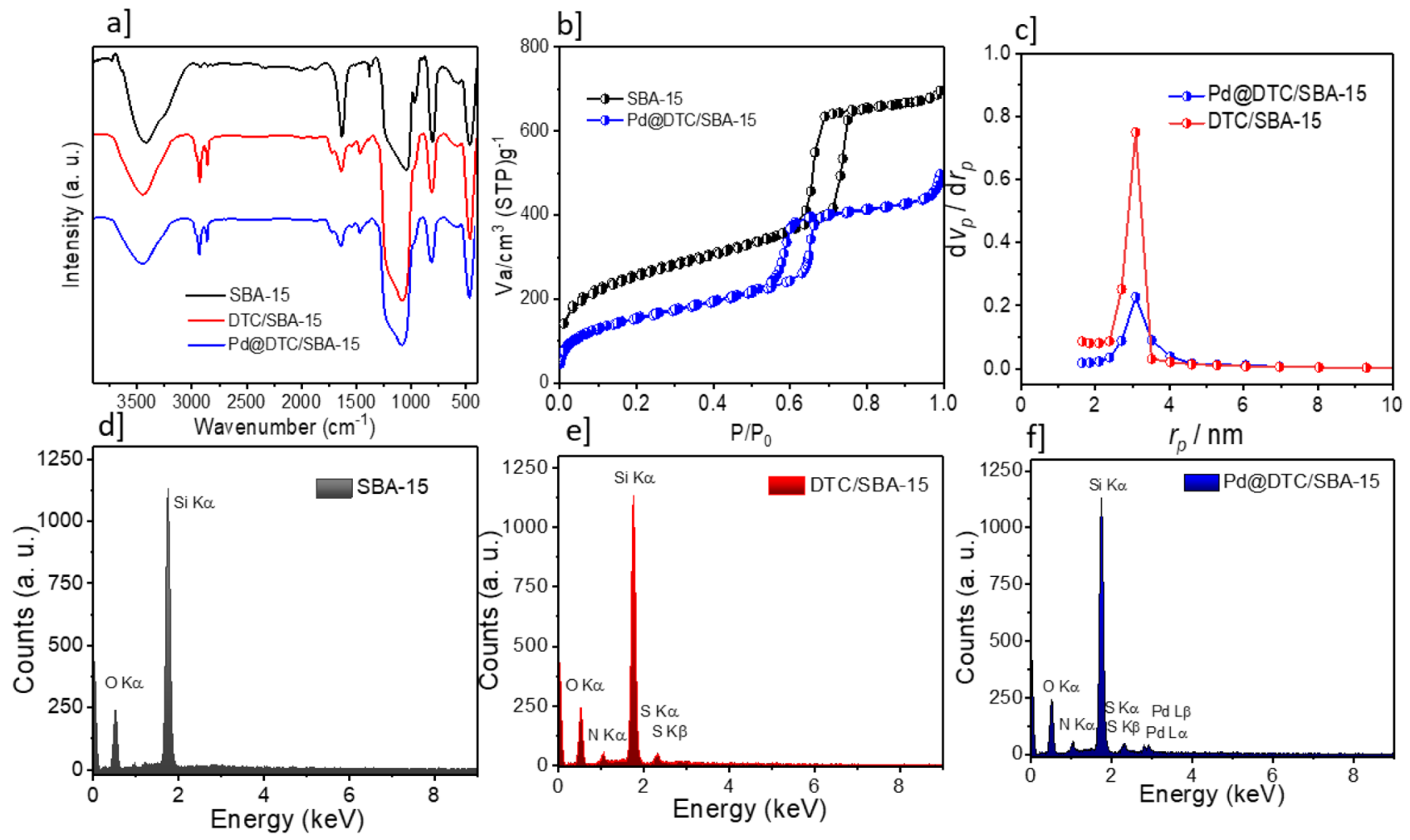

Figure 2. (a) FT-IR spectrum and (d-f) Eds analysis of SBA-15, SBA-15/DTC, $\mathrm{Pd}_{\mathrm{NPs}} @ \mathrm{SBA}-15 / \mathrm{DTC}$. (c,b) BET and BJH analysis of SBA-15/DTC, Pd $_{\mathrm{NPs}} @ S B A-15 / D T C$.

preparation of SBA-15/DTC. The specific surface areas of SBA-15/DTC and $\mathrm{Pd}_{\mathrm{NPs}} @$ SBA-15/DTC were measured via the BET method. As shown in Fig. 2b, all the catalysts exhibited type IV isotherms, reflecting the presence of the meso-size pores. The corresponding pore diameter distributions for SBA-15/DTC and Pd NPs $_{3} @ S B-15 /$ DTC were $3.39 \mathrm{~nm}$ and $3.17 \mathrm{~nm}$, respectively (Fig. 2c). Also, all DTC ligand (Fig. 2e) and Pd particles (Fig. 2f) are well-anchored onto mesoporous silica (Fig. 2d). The existence of all constituent elements (i.e., Si, C, O, N, S, and $\mathrm{Pd}$ ) in structures of $\mathrm{Pd}_{\mathrm{NPs}} @ S B A-15 / \mathrm{DTC}$ has been proved by the EDS analysis. 

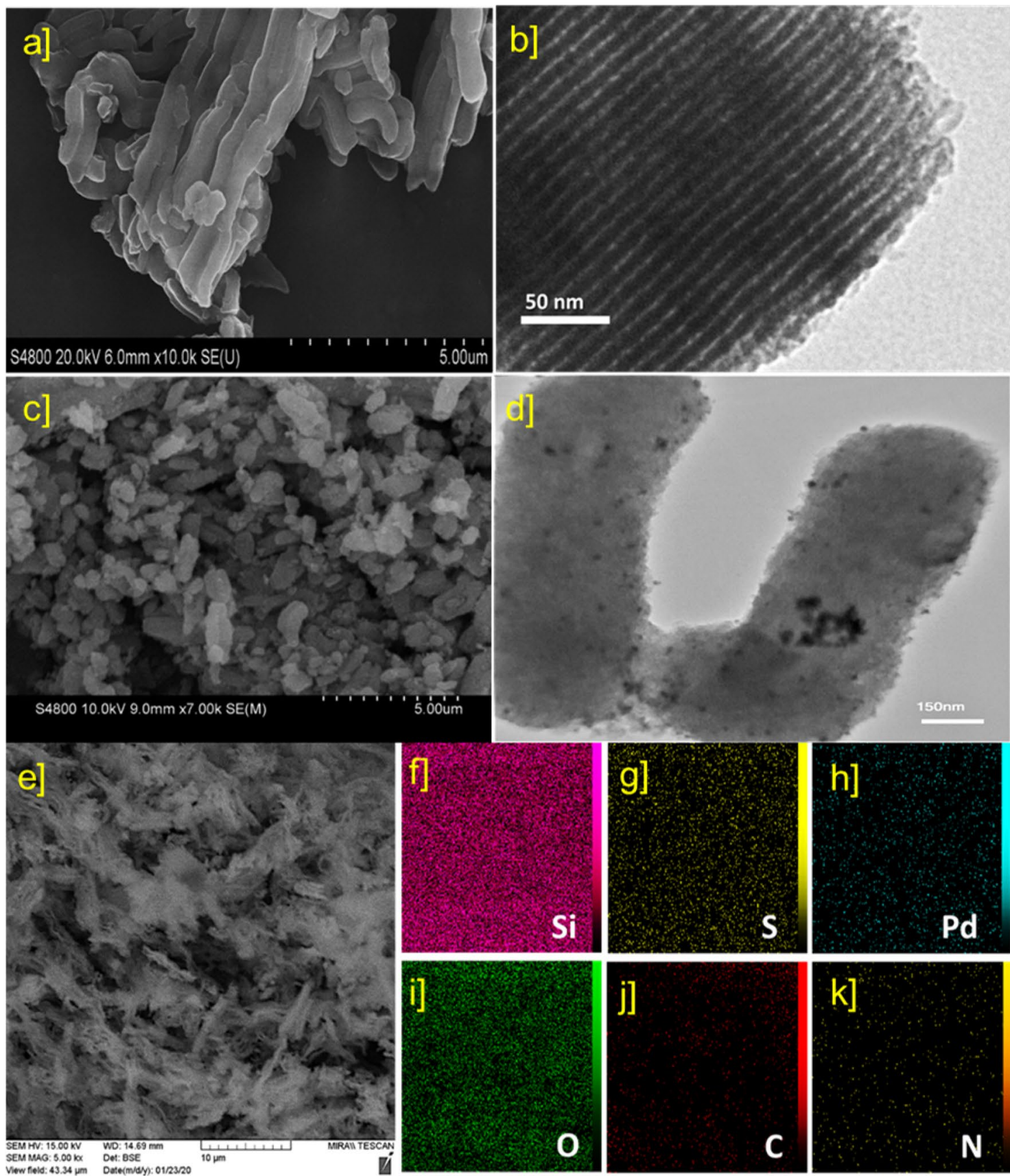

Figure 3. SEM images of (a) SBA-15/DTC and (c) $\mathrm{Pd}_{\mathrm{NPs}} @$ SBA-15/DTC. TEM images of (b) SBA-15/DTC and (d) $\mathrm{Pd}_{\mathrm{NPs}} @ S B A-15 / D T C$. (e) STEM-EDS and (f-k) elemental mappings of $\mathrm{Pd}_{\mathrm{NPs}_{\mathrm{s}}} @ S B A-15 / D T C$.

The FE-SEM image of the fabricated SBA-15/DTC indicates a rod-like morphology Fig. 3a. After deposition of Pd NPs on SBA-15/DTC surface, the rod-like structures preserve, which demonstrated NPs were orderly anchored (Fig. 3b,c). The TEM images further reveal the spherical Pd NPs that are well-distributed on the surface of the SBA-15/DTC Fig. 3d. The surface of mesoporous silica with DTC ligand helps for the stabilization of Pd NPs and inhibition of agglomeration. The STEM-EDS Fig. 3e and elemental mapping images in Fig. 3f-k proved the existence of all constituent elements (i.e., $\mathrm{Si}, \mathrm{O}, \mathrm{C}, \mathrm{N}, \mathrm{S}, \mathrm{Pd}$ ) in the mesoporous silica structure. It demonstrates the uniform distribution of Pd NPs in SBA-15/DTC channels.

Ultimately, after the characterization of meso-material, the catalytic activity of $\mathrm{Pd}_{\mathrm{NPs}} @ S B A-15 / \mathrm{DTC}$, with its comparative component for the dehydrogenation of FA at room temperature, is stated in Fig. 5a. According to Fig. 5a, $9.83 \mathrm{~mL}$ of gases are released in 120 min catalyzed by $\mathrm{Pd}_{\mathrm{NPs}_{\mathrm{s}}} @ S B A-15 / \mathrm{DTC}$, which corresponding to an initial TOF value of 1954 and TON 3904.

To evaluate the performance of $\mathrm{Pd}_{\mathrm{NPs}} @$ SBA-15/DTC (2.89 wt\% Pd, determined by ICP analysis), for catalytic $\mathrm{H}_{2}$ production, we utilize FA/SF (1: 1) as the reaction substrate. Very recently, a variety of noble metal NPs ${ }^{54-56}$ has been used to catalyze the selective dehydrogenation of FA under mild conditions. 

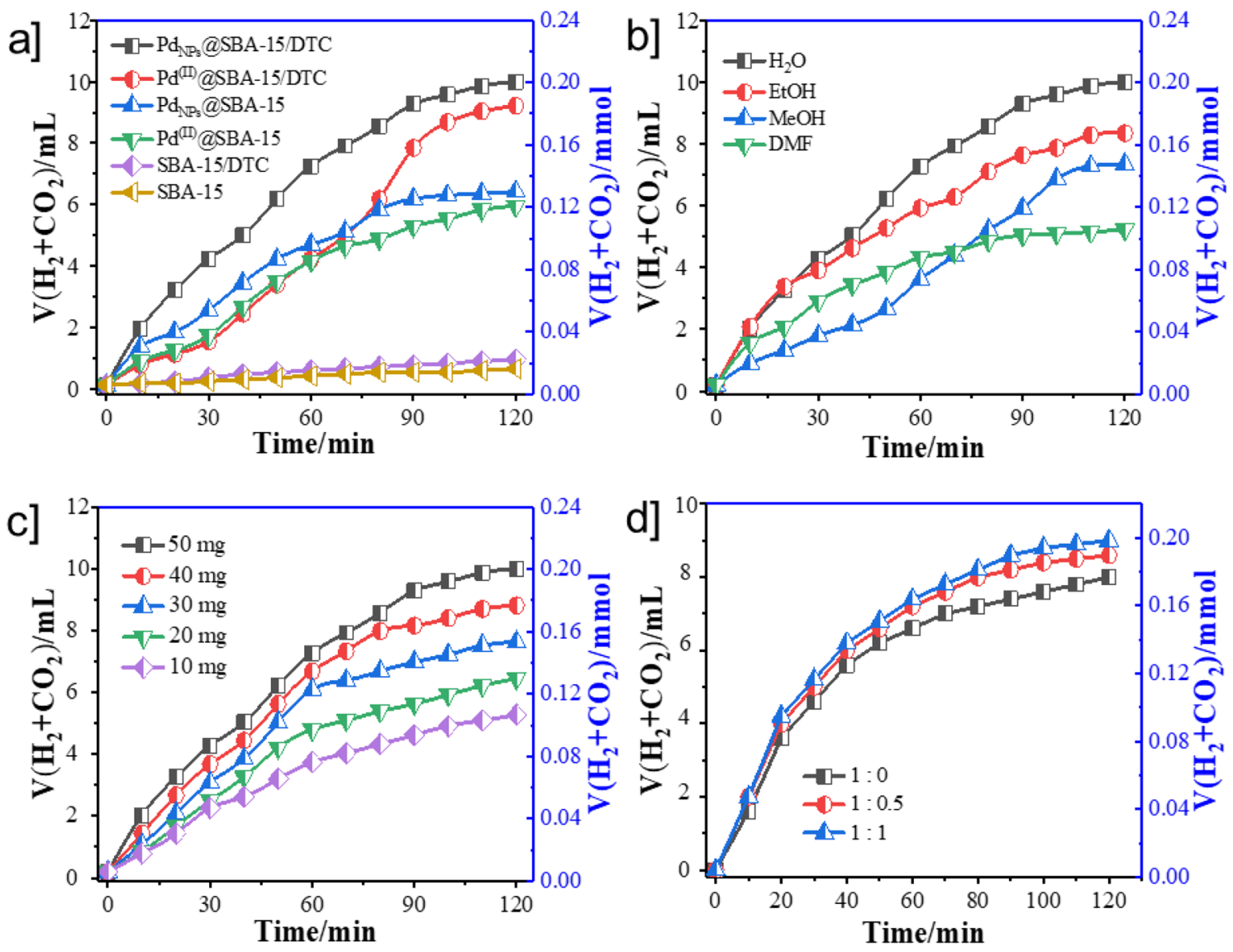

Figure 4. Volume of generated gas $\left(\mathrm{H}_{2}+\mathrm{CO}_{2}\right)$ versus time for the dehydrogenation of FA in FA-SF aqueous solution at $298 \mathrm{~K}$ over (a) different support (b) different solvents (c) amount catalyst (d) different mole ratio of FA/SF.

Figure 4a shows the evolution of $\mathrm{H}_{2}$ overtime when the Pd@SBA-15/DTC catalyst is mixed with a solution FA/SF under an ultrasonic wave. The $\mathrm{H}_{2}$ generation for FA complete (ca $0.205 \mathrm{mmol}$ and $1954 \mathrm{TOF}$ ) in $120 \mathrm{~min}$. Remarkably, $\mathrm{Pd}_{\mathrm{NP}} @ \mathrm{SBA}-15 / \mathrm{DTC}$ had catalytic activity comparable to immobilized Pd complex (Pd ${ }^{\text {(II) }} @ S B A-15 /$ DTC), Pd ${ }^{(I I)} @ S B A-15$, SBA-15/DTC, and SBA-15 without the use of any additive in presence ultrasonic wave. This result demonstrates the DTC groups can apparently elevate the electron transfer from the host to Pd NPs and thus increases activity dehydrogenation FA. Even though the $\mathrm{H}_{2}$ amount for $\mathrm{Pd}_{\mathrm{NPs}_{s}} @ S B A-15 / \mathrm{DTC}$ is more than others, we continued our investigations with encapsulated Pd NPs. For instance, when we investigated the dehydrogenation progress with various solvents such as $\mathrm{EtOH}, \mathrm{MeOH}, \mathrm{DMF}$, and $\mathrm{H}_{2} \mathrm{O}$, we found that $\mathrm{H}_{2} \mathrm{O}$ with $9.86 \mathrm{~mL} \mathrm{\textrm {H } _ { 2 }}$ gas and Tenover frequency (TOF) of 1952 is more efficient than the other solvent Fig. 4b. Using Pd NPs $_{\text {@SBA-15/ }}$ DTC, $\mathrm{CO}$ generation was insignificant (detected by $\mathrm{GC}$ and $\mathrm{NaOH}$ trap experiments), whereas $\mathrm{H}_{2}$ generation as well associates with literature data ${ }^{57,58}$. When the amount of the catalyst increased from 10 to $50 \mathrm{mg}$, the FA dehydrogenation was also increased (Fig. 4c). On the other hand, the catalytic activity of $\mathrm{Pd}_{\mathrm{NPs}} @ S B A-15 / D T C$ is enhanced by the addition of SF, and we continued our studies in the best mole ratio of FA: SF is 1:1 (Fig. 4d).

Additionally, when the reaction was tested at various temperatures, it showed that ultrasonic condition in $335 \mathrm{~K}$ accelerates the decomposition of FA reaction Fig. 5a. Because of the enhanced rate of the dehydrogenation FA at room temperature and the significant importance of associated chemical processes and energy issues, we continued our studies under ambient conditions. According to this study, the activation energy $(E a)$ of the dehydrogenation FA is $37.48 \pm 2.0 \mathrm{~kJ} \mathrm{~mol}^{-1}$ according to the Arrhenius plot, which is in agreement with previous studies Fig. 5b. The catalytic performance is related to the reaction temperature in a positive way, giving the TOF values of $1952,1985,2085$, and $2154 \mathrm{~h}^{-1}$ at the corresponding reaction temperatures Fig. $5 \mathrm{c}$, respectively. As represented in (Fig. 5d), the activity of all SBA-15 samples was enhanced under the wave of ultrasonic, and the $\mathrm{Pd}_{\mathrm{NPs}} @ S B A-15 / \mathrm{DTC}$ produce a large amount of $\mathrm{H}_{2}$ generation in comparison with that high-speed stirrer (HSS). Therefore the suggestion is that ultrasonic irradiation is the third function that acts as a synergistic agent in the catalytic decomposition of FA.

According to the promising results obtained above, $\mathrm{NaOH}$ trap experiments were performed to determine the volume ratio of $\mathrm{H}_{2}$ to $\mathrm{CO}_{2}$ in the dehydrogenation process. The produced gas was treated with/without $\mathrm{NaOH}$ trap (Fig. 6). The volume of produced gas was decreased to half after treating with the $10 \mathrm{M} \mathrm{NaOH}$ aqueous solution. The results demonstrate complete adsorption of $\mathrm{CO}_{2}$ gas in $\mathrm{NaOH}$ solution (I), and the produced gas is $\mathrm{H}_{2}$ and $\mathrm{CO}_{2}$ with the volume ratio of $1: 1$. 

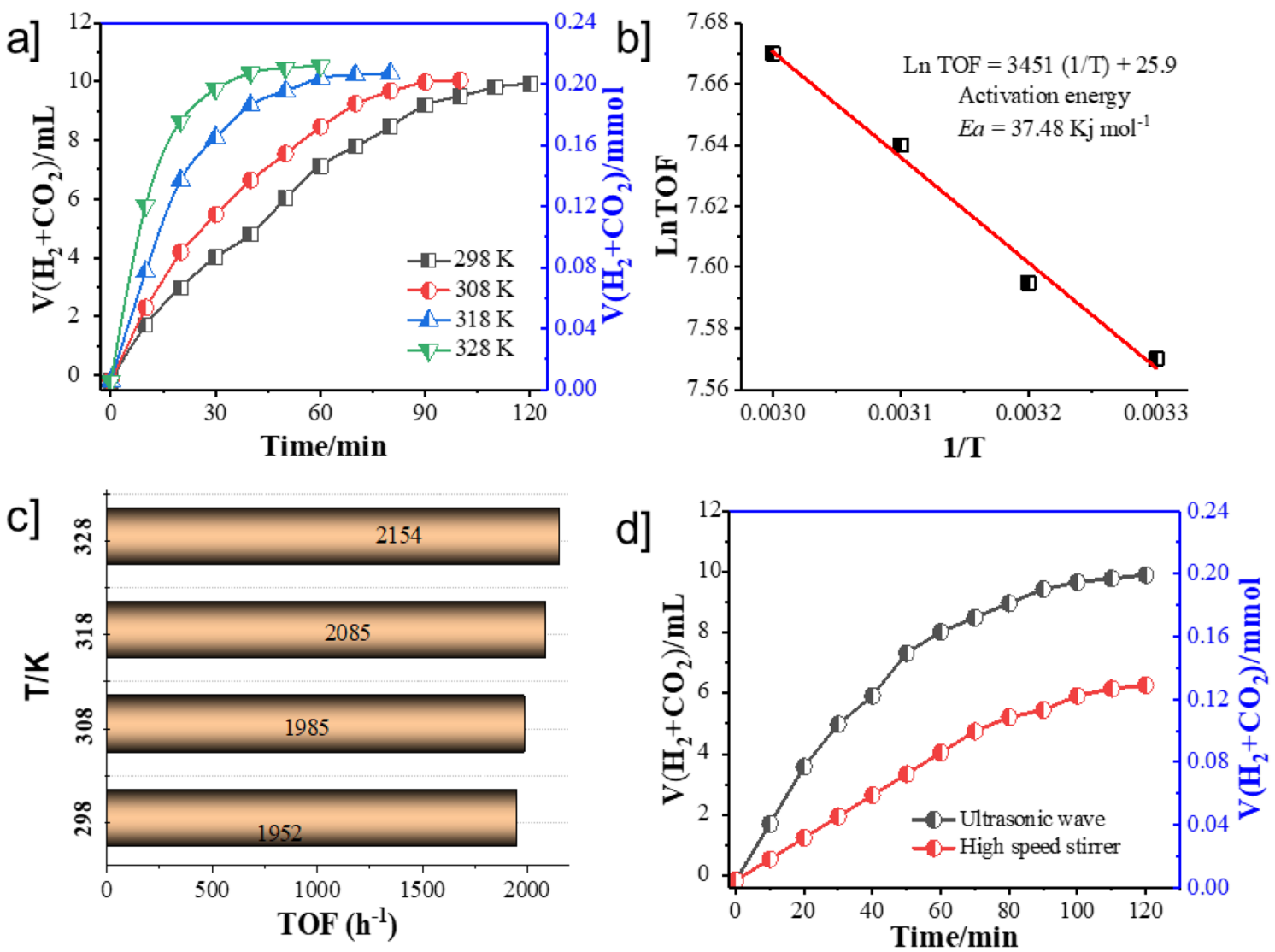

Figure 5. (a) Volume of generated gas $\left(\mathrm{H}_{2}+\mathrm{CO}_{2}\right)$ versus time for the dehydrogenation of FA without the addition of SF over $\mathrm{Pd}_{\mathrm{NPs}} @$ SBA-15/DTC at different temperature (b) corresponding kinetic parameters (c) corresponding TOF $(\mathbf{d})$ relationship between gases production under ultrasonic irradiation or stirrer over $\mathrm{Pd}_{\mathrm{NPs}} @ S B A-15 / \mathrm{DTC}$.

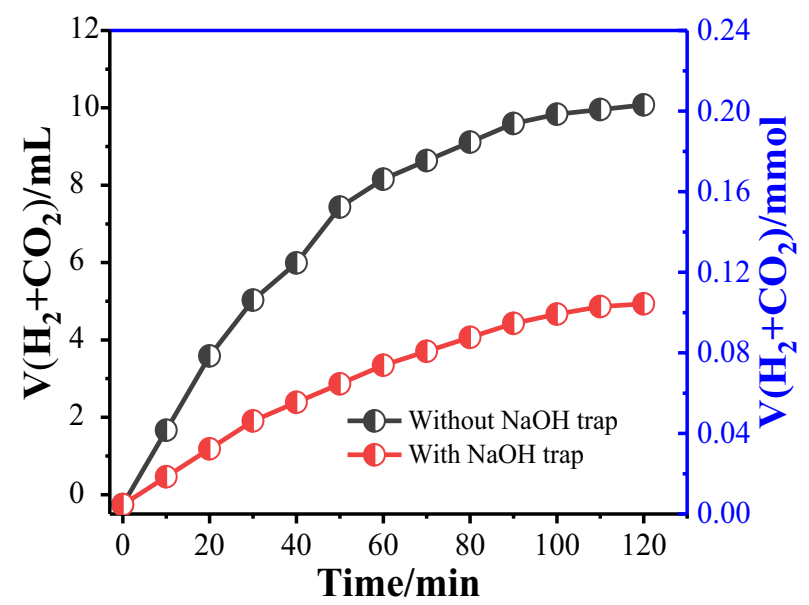

Figure 6. Volume of generated gases versus time for the dehydrogenation of FA in FA-SF aqueous solution at room temperature over $\mathrm{Pd}_{\mathrm{NPs}} @ S B A-15 / \mathrm{DTC}$ with/without $\mathrm{NaOH}$ trap.

$$
\text { (I) } \mathrm{CO}_{2}(\mathrm{~g})+2 \mathrm{NaOH}(\mathrm{l}) \rightarrow \mathrm{Na}_{2} \mathrm{CO}_{3}(\mathrm{~s})+\mathrm{H}_{2} \mathrm{O}
$$

To compare Pd-SBA-15 activity with benchmark ligands, some catalytic tests were carried out also with ligands donor electrons such as bis-thiourea (BTU), S-H and dithiocarbamate (DTC), which result presented in Table 1. In the presence of DTC ligand, $3.41 \%$ conversion was achieved in $2 \mathrm{~h}$ with maximum volume gases 


\begin{tabular}{|l|l|l|l|l|l|}
\hline Entry & Ligand & Metal & Max vol $(\mathbf{m L})[\mathbf{t}(\mathbf{m i n})]^{\mathbf{a}}$ & TOF $\left.^{\mathbf{a}} \mathbf{h}^{-\mathbf{1}}\right)^{\mathbf{b}}$ & TON tot $^{\mathbf{c}}$ \\
\hline 1 & $\mathrm{~S}-\mathrm{H}$ & $\mathrm{Pd}^{(\mathrm{II})}$ & $2.26[135]$ & 50.8 & 114.3 \\
\hline 2 & $\mathrm{~S}-\mathrm{H}$ & $\mathrm{Pd}_{\mathrm{NPs}}$ & $2.81[135]$ & 54.2 & 121.9 \\
\hline 3 & $\mathrm{BTU}$ & $\left.\mathrm{Pd}^{\mathrm{II}}\right)$ & $5.69[180]$ & 40.1 & 120.3 \\
\hline 4 & $\mathrm{BTU}$ & $\mathrm{Pd}_{\mathrm{NPs}}$ & $6.03[180]$ & 42.5 & 127.0 \\
\hline 5 & $\mathrm{DTC}$ & $\mathrm{Pd}^{(\mathrm{II})}$ & $8.76[120]$ & 1739 & 3478 \\
\hline 6 & $\mathrm{DTC}$ & $\mathrm{Pd}_{\mathrm{NPs}}$ & $9.83[120]$ & 1952 & 3904 \\
\hline
\end{tabular}

Table 1. Results of catalytic FA dehydrogenation in the presence of various ligand. Conditions: $5 \mathrm{~mL}, 5 \% \mathrm{v} / \mathrm{v}$

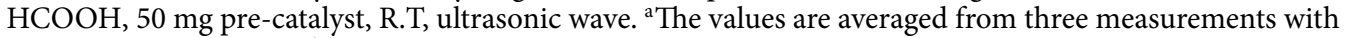
reproducibility of $\pm 5 \%$. ${ }^{b}$ Defined as $\left(\mathrm{mmol}_{\text {produced gas }} / \mathrm{mmol}_{\mathrm{Pd}}\right) \times \mathrm{h}^{-1}$. ${ }^{\mathrm{c}}$ Defined as $\left(\mathrm{mmol}_{\text {produced gas }} / \mathrm{mmol}_{\mathrm{Pd}}\right)$.

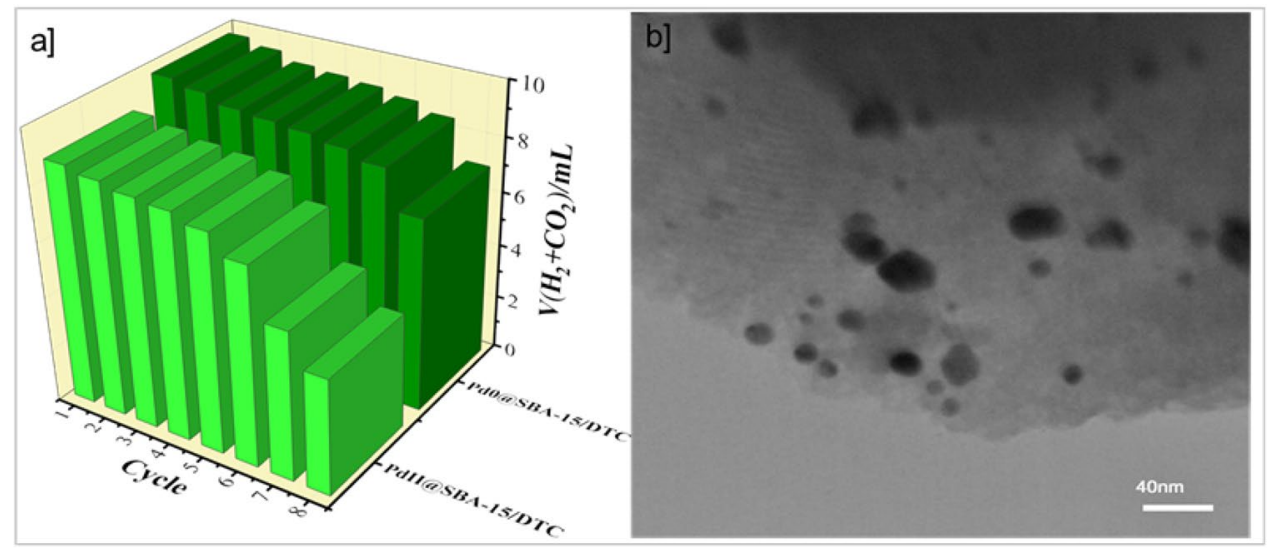

Figure 7. (a) Durability of the $\mathrm{Pd}_{\mathrm{NPs}} @ S B A-15 / \mathrm{DTC}$ and Pd ${ }^{\mathrm{II}} @ S B A-15 / \mathrm{DTC}$ (b) TEM images after the 8th recycling of $\mathrm{Pd}_{\mathrm{NPs}} @ \mathrm{SBA}-15 / \mathrm{DTC}$.

$9.86 \mathrm{~mL}$, giving the highest TOF $=1952 \mathrm{~h}^{-1}$ in comparison with other ligands stabilize Pd NPs. The results show the high efficiency of DTC ligand compared to other ligands for stabilizing and keeping Pd inactive state in the structure of SBA-15.

Finally, runs were repeated to check the activity and stability of the Pd@SBA-15, reusability tests were also performed by adding neat FA $(5 \% \mathrm{v} / \mathrm{v})$ to the reaction mixtures under the ultrasonic wave. The pre-catalysts was recovered and reactivated by common filtration after each reaction. As shown in Fig. 7a, the activity was approximately kept for the first eight-time suggesting that the Pd@SBA-15 was stable during the decomposition of FA for a long time. However, after each cycle of reaction, a small amount of decrease in yield was observed, which could be attributed to the reality that a small fraction of the catalyst is lost in each recovery. Stable mesoporous silica and Pd NPs aggregation after the reuse testified by TEM images (Fig. 7b). According to these results, the proposed catalyst after $8^{\text {th }}$ run affirming the overall structural integrity of the material without aggregation of Pd particles.

\section{Conclusion}

The purpose of the current study was to design DTC/SBA-15 as excellent support for anchoring and stabilizing $\mathrm{Pd}$ in nanoscale. The proposed catalyst shows high catalytic activity, good stability, and easy recyclability for the selective dehydrogenation of FA under ultrasonic irradiation. The results suggested that the mesoporous structure and synergistic effect of palladium metal, dithiocarbamate ligands in SBA-15 frameworks, and ultrasonic irradiation play serious roles in the catalytic performance of the $\mathrm{H}_{2}$ generation from FA. Moreover, by modifying this mesoporous material with the various organic ligands for stabilizing other noble metal nanoparticles can be developed to prepare versatile heterogeneous catalysts for organic transformations and environmental application.

Received: 29 April 2020; Accepted: 11 September 2020

Published online: 23 October 2020

\section{References}

1. Yang, J., Sudik, A., Wolverton, C. \& Siegel, D. J. High capacity hydrogen storage materials: attributes for automotive applications and techniques for materials discovery. Chem. Soc. Rev. 39, 656-675 (2010).

2. Boynuegri, T. A. \& Gürü, M. Catalytic dehydrogenation of calcium borohydride by using hydrogel catalyst. Int. J. Hydrog. Energy 42, 17869-17873 (2017).

3. Graetz, J. New approaches to hydrogen storage. Chem. Soc. Rev. 38, 73-82 (2009).

4. Grasemann, M. \& Laurenczy, G. Formic acid as a hydrogen source-recent developments and future trends. Energy Environ. Sci. 5, 8171-8181 (2012). 
5. Yadav, M. \& Xu, Q. Liquid-phase chemical hydrogen storage materials. Energy Environ. Sci. 5, 9698-9725 (2012).

6. Zhu, Q.-L. \& Xu, Q. Liquid organic and inorganic chemical hydrides for high-capacity hydrogen storage. Energy Environ. Sci. 8, 478-512 (2015).

7. Bavykina, A., Goesten, M., Kapteijn, F., Makkee, M. \& Gascon, J. Efficient production of hydrogen from formic acid using a Covalent Triazine Framework supported molecular catalyst. Chemsuschem 8, 809-812 (2015).

8. Boddien, A. et al. Ortho-metalation of iron (0) tribenzylphosphine complexes: homogeneous catalysts for the generation of hydrogen from formic acid. Angew. Chem. Int. Ed. 49, 8993-8996 (2010).

9. Fellay, C., Dyson, P. J. \& Laurenczy, G. A viable hydrogen-storage system based on selective formic acid decomposition with a ruthenium catalyst. Angew. Chem. 120, 4030-4032 (2008).

10. Fukuzumi, S., Kobayashi, T. \& Suenobu, T. Efficient catalytic decomposition of formic acid for the selective generation of $\mathrm{H}_{2}$ and H/D exchange with a water-soluble rhodium complex in aqueous solution. Chemsuschem 1, 827-834 (2008).

11. Fukuzumi, S., Kobayashi, T. \& Suenobu, T. Unusually large tunneling effect on highly efficient generation of hydrogen and hydrogen isotopes in $\mathrm{pH}$-selective decomposition of formic acid catalyzed by a heterodinuclear iridium- ruthenium complex in water. $J$. Am. Chem. Soc. 132, 1496-1497 (2010).

12. Hull, J. F. et al. Reversible hydrogen storage using $\mathrm{CO}_{2}$ and a proton-switchable iridium catalyst in aqueous media under mild temperatures and pressures. Nature chemistry 4, 383-388 (2012).

13. Sponholz, P., Mellmann, D., Junge, H. \& Beller, M. Towards a practical setup for hydrogen production from formic acid. Chemsuschem 6, 1172-1176 (2013).

14. Wang, Z., Lu, S. M., Li, J., Wang, J. \& Li, C. Unprecedentedly high formic acid dehydrogenation activity on an iridium complex with an N, N'-diimine ligand in water. Chemistry 21, 12592-12595 (2015).

15. Jiang, K., Xu, K., Zou, S. \& Cai, W.-B. B-Doped Pd catalyst: boosting room-temperature hydrogen production from formic acidformate solutions. J. Am. Chem. Soc. 136, 4861-4864 (2014).

16. Chen, Y., Zhu, Q.-L., Tsumori, N. \& Xu, Q. Immobilizing highly catalytically active noble metal nanoparticles on reduced graphene oxide: a non-noble metal sacrificial approach. J. Am. Chem. Soc. 137, 106-109 (2015).

17. Cai, Y. Y. et al. Highly Efficient Dehydrogenation of Formic Acid over a Palladium-Nanoparticle-Based Mott-Schottky Photocatalyst. Angew. Chem. 125, 12038-12041 (2013).

18. Bi, Q.-Y. et al. Efficient subnanometric gold-catalyzed hydrogen generation via formic acid decomposition under ambient conditions. J. Am. Chem. Soc. 134, 8926-8933 (2012).

19. Wang, Z. L. et al. An efficient CoAuPd/C catalyst for hydrogen generation from formic acid at room temperature. Angew. Chem. Int. Ed. 52, 4406-4409 (2013).

20. Yang, L. et al. Highly efficient hydrogen generation from formic acid-sodium formate over monodisperse AgPd nanoparticles at room temperature. Appl. Catal. B 168, 423-428 (2015).

21. Yoo, J. S., Zhao, Z.-J., Nørskov, J. K. \& Studt, F. Effect of boron modifications of palladium catalysts for the production of hydrogen from formic acid. ACS Catal. 5, 6579-6586 (2015).

22. Qin, Y. L., Liu, Y. C., Liang, F. \& Wang, L. M. Preparation of Pd-Co-based nanocatalysts and their superior applications in formic acid decomposition and methanol oxidation. Chemsuschem 8, 260-263 (2015).

23. Li, F.-F., Gu, J.-N. \& Zhou, X.-C. Single molecule electro-catalysis of non-fluorescent molecule. Chin. Chem. Lett. 26, 1514-1517 (2015).

24. Wang, Y.-X. \& Chen, T.-H. A high dispersed $\mathrm{Pt}_{0.35} \mathrm{Pd}_{0.35} \mathrm{Co}_{0.30} / \mathrm{C}$ as superior catalyst for methanol and formic acid electro-oxidation. Chin. Chem. Lett. 25, 907-911 (2014).

25. Yi, N., Saltsburg, H. \& Flytzani-Stephanopoulos, M. Hydrogen production by dehydrogenation of formic acid on atomically dispersed gold on ceria. Chemsuschem 6, 816-819 (2013).

26. Marković, N. \& Ross, P. Jr. Surface science studies of model fuel cell electrocatalysts. Surf. Sci. Rep. 45, 117-229 (2002).

27. Li, S. J. et al. A simple and effective principle for a rational design of heterogeneous catalysts for dehydrogenation of formic acid. Adv. Mater. 31, 1806781 (2019).

28. Martis, M., Mori, K., Fujiwara, K., Ahn, W.-S. \& Yamashita, H. Amine-functionalized MIL-125 with imbedded palladium nanoparticles as an efficient catalyst for dehydrogenation of formic acid at ambient temperature. J. Phys. Chem. C 117, 22805-22810 (2013).

29. Hong, W. et al. Immobilization of highly active bimetallic PdAu nanoparticles onto nanocarbons for dehydrogenation of formic acid. J. Mater. Chem. A 7, 18835-18839 (2019).

30. Ye, W. et al. Controlling the synthesis of uniform electron-deficient Pd clusters for superior hydrogen production from formic acid. J. Mater. Chem. A 7, 10363-10371 (2019).

31. Karatas, Y. et al. $\mathrm{PdAu}-\mathrm{MnOx}$ nanoparticles supported on amine-functionalized $\mathrm{SiO}_{2}$ for the room temperature dehydrogenation of formic acid in the absence of additives. Appl. Catal. B 180, 586-595 (2016).

32. Yurderi, M. et al. Amine grafted silica supported CrAuPd alloy nanoparticles: superb heterogeneous catalysts for the room temperature dehydrogenation of formic acid. Chem. Commun. 51, 11417-11420 (2015).

33. Luo, Y. et al. Anchoring IrPdAu nanoparticles on NH2-SBA-15 for fast hydrogen production from formic acid at room temperature. ACS Appl. Mater. Interfaces. 12, 8082-8090 (2020).

34. Li, S.-J. et al. Facile synthesis of AgAuPd/graphene with high performance for hydrogen generation from formic acid. J. Mater. Chem. A 3, 14535-14538 (2015).

35. Wen, M., Mori, K., Kuwahara, Y. \& Yamashita, H. Plasmonic Au@ Pd nanoparticles supported on a basic metal-organic framework: synergic boosting of $\mathrm{H} 2$ production from formic acid. ACS Energy Lett. 2, 1-7 (2016).

36. Gu, X., Lu, Z.-H., Jiang, H.-L., Akita, T. \& Xu, Q. Synergistic catalysis of metal-organic framework-immobilized Au-Pd nanoparticles in dehydrogenation of formic acid for chemical hydrogen storage. J. Am. Chem. Soc. 133, 11822-11825 (2011).

37. Caner, N. et al. Atomic layer deposition- $\mathrm{SiO}_{2}$ layers protected PdCoNi nanoparticles supported on $\mathrm{TiO}_{2}$ nanopowders: Exceptionally stable nanocatalyst for the dehydrogenation of formic acid. Appl. Catal. B 210, 470-483 (2017).

38. Alamgholiloo, H. et al. Synthesis of bimetallic 4-PySI-Pd@ Cu (BDC) via open metal site Cu-MOF: effect of metal and support of Pd@ Cu-MOFs in H2 generation from formic acid. Mol. Catal. 467, 30-37 (2019).

39. Alamgholiloo, H. et al. Formation and stabilization of colloidal ultra-small palladium nanoparticles on diamine-modified CrMIL-101: Synergic boost to hydrogen production from formic acid. J. Colloid Interface Sci. 567, 126-135 (2020).

40. Wang, Z., Zeng, J., Song, H. \& Li, F. Research on ultrasonic excitation for the removal of drilling fluid plug, paraffin deposition plug, polymer plug and inorganic scale plug for near-well ultrasonic processing technology. Ultrason. Sonochem. 36, 162-167 (2017).

41. Cheng, Z., Xue, Y. \& Ju, H. Chemical coloring on stainless steel by ultrasonic irradiation. Ultrason. Sonochem. 40, 558-566 (2018).

42. Mohsin, M. \& Meribout, M. Oil-water de-emulsification using ultrasonic technology. Ultrason. Sonochem. 22, 573-579 (2015).

43. Parast, M. S. Y. \& Morsali, A. Sonochemical-assisted synthesis of nano-structured indium (III) hydroxide and oxide. Ultrason. Sonochem. 18, 375-381 (2011).

44. Mallakpour, S. \& Nouruzi, N. Effect of modified ZnO nanoparticles with biosafe molecule on the morphology and physiochemical properties of novel polycaprolactone nanocomposites. Polymer 89, 94-101 (2016).

45. Kumar, D. et al. Supported protic acid-catalyzed synthesis of 2, 3-disubstituted thiazolidin-4-ones: enhancement of the catalytic potential of protic acid by adsorption on solid supports. Green Chem. 15, 2872-2884 (2013). 
46. Park, M.-H. et al. Chemically directed immobilization of nanoparticles onto gold substrates for orthogonal assembly using dithiocarbamate bond formation. ACS Appl. Mater. Interfaces. 2, 795-799 (2010).

47. Zhao, Y., Pérez-Segarra, W., Shi, Q. \& Wei, A. Dithiocarbamate assembly on gold. J. Am. Chem. Soc. 127, 7328-7329 (2005).

48. Gao, D. et al. Fabrication of asymmetric molecular junctions by the oriented assembly of dithiocarbamate rectifiers. J. Am. Chem. Soc. 133, 5921-5930 (2011).

49. Zhao, D. et al. Triblock copolymer syntheses of mesoporous silica with periodic 50 to 300 angstrom pores. Science $\mathbf{2 7 9}, 548-552$ (1998).

50. Crudden, C. M., Sateesh, M. \& Lewis, R. Mercaptopropyl-modified mesoporous silica: a remarkable support for the preparation of a reusable, heterogeneous palladium catalyst for coupling reactions. J. Am. Chem. Soc. 127, 10045-10050 (2005).

51. Sawant, D. P. et al. Heteropoly acid encapsulated SBA-15/TiO2 nanocomposites and their unusual performance in acid-catalysed organic transformations. Chemistry 14, 3200-3212 (2008).

52. Balasubramanian, V. et al. Characterization and the catalytic applications of mesoporous AlSBA-1. Microporous Mesoporous Mater. 121, 18-25 (2009).

53. Balasubramanian, V. et al. Highly active three-dimensional cage type mesoporous aluminosilicates and their catalytic performances in the acetylation of aromatics. Microporous Mesoporous Mater. 114, 303-311 (2008).

54. Liu, H. et al. Photocatalytic dehydrogenation of formic acid promoted by a superior PdAg@ $\mathrm{gC}_{3} \mathrm{~N}_{4}$ Mott-Schottky heterojunction. J. Mater. Chem. A 7, 2022-2026 (2019).

55. Hong, C.-B., Ma, D.-D., Wu, X. \& Zhu, Q.-L. An effective amino acid-assisted growth of ultrafine palladium nanocatalysts toward superior synergistic catalysis for hydrogen generation from formic acid. Inorg. Chem. Front. 6, 975-981 (2019).

56. Koh, K., Jeon, M., Yoon, C. W. \& Asefa, T. Formic acid dehydrogenation over Pd NPs supported on amine-functionalized SBA-15 catalysts: structure-activity relationships. J. Mater. Chem. A 5, 16150-16161 (2017).

57. Feng, C. et al. AgPd nanoparticles supported on zeolitic imidazolate framework derived N-doped porous carbon as an efficient catalyst for formic acid dehydrogenation. RSC Adv. 5, 39878-39883 (2015).

58. Dai, H. et al. Synergistic catalysis of AgPd@ ZIF-8 on dehydrogenation of formic acid. Appl. Catal. B 165, 57-62 (2015).

\section{Author contributions}

H.A worked the project and wrote the main manuscript text. M.F, F.N and R.B did the experiments. S.R managed the work and supervised the project.

\section{Competing interests}

The authors declare no competing interests.

\section{Additional information}

Correspondence and requests for materials should be addressed to S.R.

Reprints and permissions information is available at www.nature.com/reprints.

Publisher's note Springer Nature remains neutral with regard to jurisdictional claims in published maps and institutional affiliations.

(c) (i) Open Access This article is licensed under a Creative Commons Attribution 4.0 International License, which permits use, sharing, adaptation, distribution and reproduction in any medium or format, as long as you give appropriate credit to the original author(s) and the source, provide a link to the Creative Commons licence, and indicate if changes were made. The images or other third party material in this article are included in the article's Creative Commons licence, unless indicated otherwise in a credit line to the material. If material is not included in the article's Creative Commons licence and your intended use is not permitted by statutory regulation or exceeds the permitted use, you will need to obtain permission directly from the copyright holder. To view a copy of this licence, visit http://creativecommons.org/licenses/by/4.0/.

(c) The Author(s) 2020 